\title{
Design of a distribution network for the school lunch program
}

DOI:10.36909/jer.12815

\author{
Ayyuce Aydemir-KARADAG*, Erol AKDERE \\ Department of Industrial Engineering, Cankaya University, Eskisehir Yolu 29. Km, Etimesgut, Ankara 06790, Turkey \\ *Corresponding author: aykaradag@cankaya.edu.tr
}

\begin{abstract}
The national school lunch program (NSLP) is crucial for providing healthy, inexpensive, or free lunches to children, thus benefiting society. Designing a distribution network for the program requires solving a location and routing problem. In this paper, first, we formulate a multi-objective non-linear integer programming formulation of the problem. Next, we develop a two-step approach since the problem is Np-hard. The first stage presents a K-mean clustering method that deals with routing decisions by determining the locations of food processing centers and allocating schools to these centers. The second stage offers a multi-objective mixed-integer linear mathematical model for finding the locations of distribution centers. Besides economic and environmental factors, we optimize travel time in the network as perishable items are involved. A weighted sum approach is presented for different weights of objectives. We provide a real case study in Turkey to demonstrate the applicability of the two-stage approach proposed in this study. The numerical results provide valuable information for decision-makers and authorities to prioritize and prepare action plans.
\end{abstract}

Keywords: Facility Location; K-Means Clustering Method; Modeling; School Lunch Program 


\section{INTRODUCTION}

The National School Lunch Program (NSLP) is a government-sponsored catering program implemented in public and non-profit private schools (Ralston et al., 2008). It offers children healthy, cheap, or free lunch every day at school. Providing school lunch programs is crucial to tackling persistent inequalities such as child poverty as more and more children worldwide are starving. Child poverty drives poor children out of school, forcing them to work and take on adult responsibilities at school age. The continuity of this process causes these children to become unqualified in the future and work in jobs without social security and almost guarantees the possibility of experiencing income poverty again throughout their lives (Candaş et al., 2011). It is estimated that $16 \%$ of the child's total consumption of hot meals can be met with school lunch, which corresponds to about $10 \%$ of the expenses for a child in a low-income family (Bundy et al., 2009). Besides, meeting a part of the child's nutritional needs increases the child's life quality in the short and long term and reduces inadequate and unbalanced nutrition and health problems, and plays an essential role in gaining healthy eating habits at young ages (FRAC, 2021). In many countries, it is known that families' economic conditions affect girls' education more negatively. A study conducted by the World Food Program in 4000 primary schools in 32 Sub-Saharan African countries showed that the NSLP reduces this gender-based discrimination and effectively increases the enrollment rate, especially for girls (Bundy et al., 2009). The total enrollment rate is increased by $28 \%$ for girls and $22 \%$ for boys during the first year of school feeding assistance (Bundy et al., 2009). NSLP is an incentive to send children to school and continue their education.

Due to all these multidimensional benefits of NSLP, more than a hundred countries with different developmental levels around the world, such as Norway, Japan, Chile, India, Ireland, Sweden, the United States, and Brazil, offer free school meals to their students (Candaş et al., 2011). 
In addition, NSLP was launched in 72 countries with the support of the United Nations World Food Program. Some of these countries are Kenya, El Salvador, Ecuador, Pakistan, Haiti, Sudan, Indonesia, Malawi, and Afghanistan (Candaş et al., 2011). We note that NSLP has not been implemented in any region of Turkey before. The Ministry of National Education of Turkey is currently planning to give free school lunch to 18.5 million students across the country in the 20202021 academic year (Milliyet, 2020). The program will start in the priority regions selected as a pilot area and gradually spread throughout the country. The plans of Turkey on NSLP motivate us to design a distribution network for this program. The outputs provide valuable information to decision-makers, such as locations of distribution centers (DCs), food processing centers (FPCs), and transportation of food among the centers. The Central Anatolia region was selected as the pilot area because it is the second region in Turkey with the highest schooling rate.

The design of NSLP requires solving an NP-hard problem that addresses both location and routing decisions. Since the problem size in the real-life case study is very large, with 2589 schools, it is hard to obtain optimal solutions for this problem using exact solution methods. Therefore, we provide an alternative approach that enables us to bypass the problem's high complexity level. The alternative solution consists of two stages, where a clustering analysis is performed and a mathematical modeling formulation is solved, respectively. The cluster centers represent the locations of FPCs; thus, allocating schools to cluster centers is also determined. We assume that FPCs are close enough to serve schools on time. Therefore there is no need to solve the vehicle routing problem between schools. The second stage presents a multi-objective mixed-integer linear programming (MILP) formulation, in which binary and continuous decision variables take place together, and optimizes the locations of DCs, the flow of perishable food between the supply chain partners, and the number of heterogeneous vehicles. To the best of our knowledge, there is no effort to solve and model the problem under consideration for the school lunch program in the existing 
relevant literature. We aim to minimize the total transportation, fixed and total carbon emission costs, and total transportation time from farmers and FPCs. To handle the multi-objective nature of the problem, we used a weighted sum approach.

The remainder of the paper is organized as follows. Section 2 provides an overview of the relevant literature. We then present the problem definition and mathematical formulations in Section 3. Solution methodology is given in Section 4. We provide the details of our realistic case study in Section 5 and discuss solutions in Section 6. Conclusions and future work are noted in Section 7.

\section{LITERATURE REVIEW}

The school lunch program requires to design of a perishable food supply chain. Therefore, this section presents the existing literature on location, inventory, and routing problems in the perishable food supply chain. Orjuela-Castro et al. (2017) focus on the location problem in perishable agricultural food supply chains for mountainous urban areas. They propose a mixed-integer programming formulation (MIP) to locate collection centers and companies processing perishable foods, including losses due to temperature and relative humidity changes in mountain regions. Drezner \& Scott (2013) extend this problem by considering inventory decisions. They attempt to minimize the transportation cost and the inventory cost at the demand points. Two solution algorithms, a heuristic generalized Weiszfeld algorithm and a big triangle small triangle global optimization technique are presented. Dai et al. (2018) formulate a mixed-integer non-linear programming model (MINLP) that optimizes the number of plants and warehouses and the inventory levels in the warehouses. The model aims to minimize the total cost and includes emissions and fuzzy capacity constraints. They develop a hybrid genetic algorithm and a hybrid harmony search to solve the problem. Ghezavati et al. (2015) present a MIP for the multi-echelon distribution of the fresh tomato supply chain, which considers the freshness and ripeness of products. The model's primary goal is to optimize the distributor's profit impacting the logistics decisions 
regarding delivering fresh goods in the agri-food supply chain. Benders' decomposition method is proposed to solve the problem.

Some of the studies integrate location decisions with routing decisions in food supply chains. Govindan et al. (2014) propose a multi-objective optimization model for the two-echelon location routing problem (LRP) with time windows. They optimize both economic and environmental objectives and develop a hybrid metaheuristic approach to solve the problem. Biuki et al. (2020) present a two-step procedure for the same problem. The first step selects sustainable-oriented suppliers using a Preference Ranking Organization METHod for Enrichment Evaluation (PROMETHEE), and the second step solves a multi-objective MIP. Since the problem is Np-hard, parallel and series combinations of the Genetic Algorithm (GA) and Particle Swarm Optimization (PSO) are constructed to solve large-sized problems. Hiassat et al. (2017) present a MIP that minimizes transportation and inventory holding costs within a given period considering shelf-lives of products and the number of homogeneous vehicle fleets with a given capacity. A GA is developed to solve the proposed model. Rafie-Majd et al. (2018) formulate the LRP as an MINLP, assuming that perishable products are distributed to customers with heterogeneous vehicles within a limited time frame consisting of multiple periods and that retailers' demand is stochastic. The Lagrangian relaxation approach is used to find a lower bound, and a heuristic algorithm is constructed to get a feasible solution and an upper bound of the problem.

There are few papers in the literature that address the decisions for establishing an NSLP. Two of them focus on the auction process of the program. Epstein et al. (2004) attempt to design a meal auction system in Chile. They formulate a MIP to assign the meal contracts. The resulting model leads to significant improvements in efficiency and contributes to making the auction process more transparent. Olivares et al. (2012) provide an econometric study for a large-scale auction for Chile's school meals. They suggest novel and substantive insights regarding bidding behavior in this type of 
auction. There is only one study evaluating the school lunch program within the framework of the supply chain. Kretschmer et al. (2014) discuss the critical factors that affect the school lunch supply chain's performance and sustainability. The analysis is based on a framework for Laos in Southeast Asia. Their study shows that local supply chain models that encourage local funding, local suppliers, and local control of the system are more beneficial.

The preceding discussion on the existing relevant literature reveals that there is no effort to solve and model the problem under consideration for the school lunch program. This paper presents a mathematical formulation of the multi-echelon location routing problem in the context of school lunch distribution and a solution approach to practically solve large-size real-life problems. The formulation is an MINLP as it includes both binary and continuous variables and non-linear constraints. Besides, we test the solution methods for a selected region in Turkey. The numerical results of the case study provide essential information such as the location and number of centers, the number of vehicles, and the total cost of the program for the region where the school lunch program is planned to be implemented soon.

\section{PROBLEM DESCRIPTION AND FORMULATION}

The school lunch program distribution network (Figure 1) includes local farmers, distribution centers, food processing centers, and schools. DCs are the centers where the food received from farmers are sorted and distributed to FPCs. FPCs are the centers where the food is processed, cooked, and get ready to be distributed to schools. We assume that schools' demand is known and deterministic. The problem involves determining DC and FPC locations, allocating schools to FPCs, and routing decisions between schools. There are three levels in the network, and transportation and routing are carried out by heterogeneous vehicles at each echelon.

There are sets of $F$ farmers, $R$ DCs, $G$ FPCs, and $C$ schools in the network. $T, K, V$ correspond to sets of the heterogeneous vehicle fleets in each echelon, respectively. Vehicles have different $C V$ 
capacities and $S$ speeds. The average price per unit weight of $\mathrm{CO}_{2}\left(P C \mathrm{O}_{2}\right)$, the weight of $\mathrm{CO}_{2}$ emission per liter consumption of fuel $\left(\mathrm{WCO}_{2}\right)$, and volume of fuel consumption per unit distance per unit vehicle weight $\left(V_{\text {eff }}\right)$ are the same for all vehicles. The weight of each delivered product is represented by $W$. Each arc $(i, j)$ on the network is associated with a non-negative distance $l_{i j}, i, j \in$ $\{F \cup R \cup G \cup C\}$ and the cost of the arc $\left(c_{i j}\right)$ depends on the vehicle type. All nodes have $C F_{i}$ capacities and schools have demands of $d_{c}$.

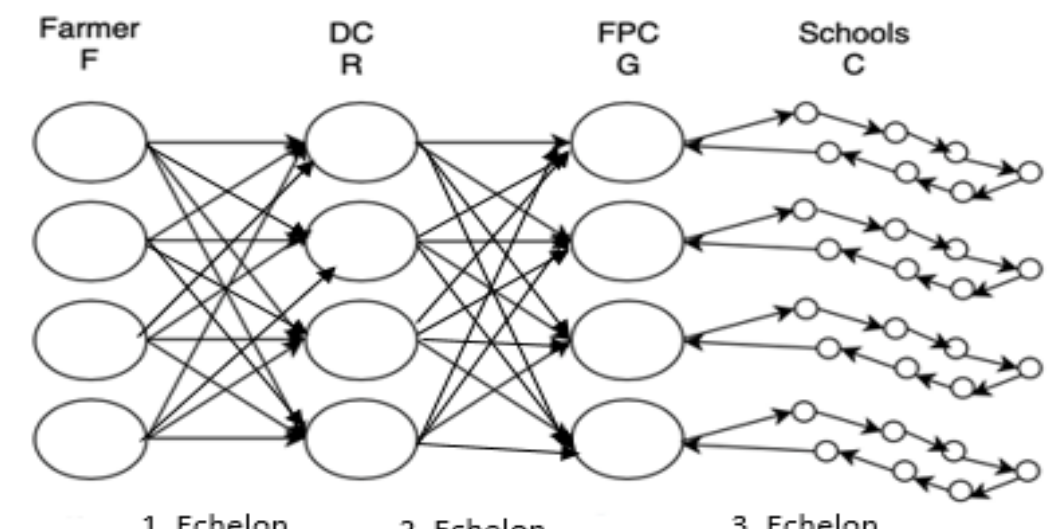

1. Echelon 2. Echelon 3. Echelon

Figure 1. Network representation for NSLP

\section{Decision variables}

$y_{g c} \quad 1$, if school $c$ is assigned to FPC $g, c \in C, g \in G$

$w_{r g}$ 1, if FPC $g$ is assigned to DC $r, g \in G, r \in R$

$z_{g} \quad 1$, if FPC $g$ is established, $g \in G$

$z_{r}^{\prime} \quad 1$, if $\mathrm{DC} r$ is established, $r \in R$

$x_{f r}^{t} \quad$ Quantity sent from farmer $f$ to DC $r$ by vehicle type $t, r \in R, f \in F, t \in T$

$x_{r g}^{\prime k} \quad$ Quantity sent from DC $r$ to FCP $g$ by vehicle type $k, r \in R, g \in G, k \in K$

$p_{f r}^{t} \quad 1$, if vehicle $t \in T$ travels from farmer $f$ to $D C r ; f \in F, r \in R, t \in T$

$p_{r g}^{k} \quad 1$, if vehicle $k \in K$ travels from $D C r$ to FPC $g ; r \in R, g \in G, \mathrm{k} \in K$ 
$q_{v} \quad 1$, if vehicle $v \in V$ is used, $v \in V$

$p_{i j}^{v} \quad 1$, if vehicle $v \in V$ travels from node $i$ to node $j ; i, j \in G \cup C, v \in V$

$d_{g}^{\prime} \quad$ Demand for FPC $g, g \in G$.

The multi-objective MINLP formulation of the problem is as follows:

$\min \sum_{r \in R} F_{r} z_{r}^{\prime}+\sum_{g \in G} F_{g} z_{g}+$

$\sum_{v \in V} F_{v} q_{v}+\sum_{t \in T} \sum_{f \in \mathrm{F}} \sum_{r \in \mathrm{R}} F_{t} p_{f r}^{t}+\sum_{k \in K} \sum_{g \in \mathrm{G}} \sum_{r \in \mathrm{R}} F_{k} p_{r g}^{k}+\sum_{v \in V} \sum_{i \in G \cup C} \sum_{j \in G \cup C} l_{i j} c_{i j}^{v} p_{i j}^{v}+$

$\sum_{f \in F} \sum_{r \in R} \sum_{\mathrm{t} \in T} x_{f r}^{t} c_{f r}^{t}+\sum_{r \in R} \sum_{g \in G} \sum_{k \in K} x_{r g}^{\prime k} c_{r g}^{k}+$

$\sum_{f} \sum_{r} \sum_{t} x_{f r}^{t} \mathrm{PCO}_{2} W \mathrm{CO}_{2} V_{e f f} l_{f r} W+\sum_{r} \sum_{g} \sum_{k} x_{r g}^{\prime k} \mathrm{PCO}_{2} W \mathrm{CO}_{2} V_{e f f} l_{r g} W$

$\operatorname{Min} \sum_{f} \sum_{r} \sum_{t} \frac{l_{f r}}{S_{t}} p_{f r}^{t}+\sum_{r} \sum_{g} \sum_{k} \frac{l_{r g}}{S_{k}} p_{r g}^{k}$

Eq (1) includes establishment costs of FPCs and DCs, fixed costs of vehicles, transportation and $\mathrm{CO} 2$ emission costs in the first two echelons. Eq (2) is the total time between farmers and DCs and DCs and FPCs.

\section{The first and second echelons}

$$
\begin{array}{ll}
\sum_{r \in R} w_{r g}=z_{g} & \forall g \in G \\
z_{r}^{\prime} \geq w_{r g} & \forall g \in G, r \in R \\
d_{g}^{\prime}=\sum_{c \in C} d_{c} y_{g c} & \forall g \in G \\
\sum_{r \in R} \sum_{t \in T} x_{f r}^{t} z_{r}^{\prime} \leq C F_{f} & \forall f \in F \\
\sum_{r \in R} \sum_{\mathrm{k} \in K} x_{r g}^{\prime k}=d_{g}^{\prime} & \forall g \in G \\
\sum_{f \in F} \sum_{\mathrm{t} \in T} x_{f r}^{t}=\sum_{g \in G} d_{g}^{\prime} w_{r g} & \forall r \in R \\
\sum_{f \in F} \sum_{\mathrm{t} \in T} x_{f r}^{t} \leq C R_{r} z_{r}^{\prime} & \forall r \in R \\
d_{g}^{\prime} \leq C G_{g} z_{g} & \forall g \in G \\
\sum_{r \in R} x_{f r}^{t} p_{f r}^{t} \leq C V_{t} & \forall t \in T, f \in \mathrm{F}
\end{array}
$$




$$
\sum_{g \in \mathrm{G}} x_{r g}^{k} p_{r g}^{k} \leq C V_{k} \quad \forall k \in \mathrm{K}, r \in \mathrm{R}
$$

Constraints (3) are single sourcing constraints that impose that a school is served by only one FPC. Constraints (4) state that a DC can serve an FPC at node $r$ if established. Constraints (5) specify that FPC's total demand at node $g$ equals the total demand of customers assigned to it. Constraints (6) indicate that the total amount of food transported to DCs cannot exceed the farmer's capacity. Constraints (7) ensure that the total amount of food transported to each FPC must satisfy its demand, which equals the total demand of customers assigned to it. Constraints (8) are the flow balance constraints for DCs. Constraints (9) and (10) indicate that the capacity of DCs and FPCs cannot be exceeded. Constraints (11) and (12) impose that the vehicle capacities cannot be exceeded.

\section{The third echelon}

$$
\begin{array}{ll}
\sum_{g \in G} y_{g c}=1 & \forall c \in C \\
y_{g c} \leq z_{g} & \forall c \in C, g \in G \\
\sum_{v \in V} \sum_{j \in G \cup C} p_{c j}^{v}=1 & \forall c \in C \\
\sum_{i \in G \cup C} p_{i j}^{v}-\sum_{j \in G \cup C} p_{j i}^{v}=0 & \forall v \in v, j \in G \cup C \\
\sum_{i \in C^{\prime}} \sum_{j \in C^{\prime}} p_{i j}^{v} \leq\left|C^{\prime}\right|-1 & \forall v \in V, C^{\prime} \subseteq C,\left|C^{\prime}\right| \geq 2 \\
\sum_{g \in G} \sum_{c \in C} p_{g c}^{v} \leq 1 & \forall v \in V \\
\sum_{j \in G \cup C} p_{c j}^{v}+\sum_{j \in G \cup C} p_{g j}^{v}-y_{g c} \leq 1 & \forall g \in G, c \in C, v \in V \\
\sum_{c \in C} \sum_{j \in G \cup C} d_{c} p_{j c}^{v} \leq C V_{v} q_{v} & \forall v \in V
\end{array}
$$

Constraints (13) impose that each school is served by only one FPC. Constraints (14) state that a school can be served by only one FPC if established. Constraints (15) ensure that each school is visited by exactly one vehicle. Constraints (16) guarantee a vehicle to return to its original destination (FPC). Constraints (17) are sub-tour elimination constraints. Constraints (18) state that a vehicle must be assigned to at most one FPC. Constraints (19) ensure that an FPC serves a school at 
node $c$ if there exits one vehicle $v$ that leaves this FPC in node $g$ and arrives at school at node $c$. Constraints (20) limit vehicle capacities.

\section{SOLUTION METHODOLOGY}

We note that the problem is Np-hard (Nagy \& Salhi, 2007; Wang et al., 2018), and its formulation is non-linear. To effectively solve large-size real-life problems, we reduce the proposed problem to a location-allocation problem. We do not neglect routing decisions; however, we assume that FPCs can serve schools on time if the best locations for FPCs can be determined, considering the demands and proximity of schools.

In the first step of our solution methodology, we determine the locations of the FPCs using the K-means clustering method. Clustering analysis is the primary exploratory statistic method for aggregating big data (Jokinen et al., 2019), which is successfully applied to many problems in supply chain design (Manzini \& Bindi, 2009; Wang et al., 2018). The primary goal of clustering analysis is to group elements into clusters according to their similarities, such as demands, density, distance, etc. K-means algorithm starts with $n$ cluster centers, and the schools are allocated to one of the existing clusters according to their proximity and demand. The centroid of each cluster is then updated, considering the membership of each cluster. These assignment and update processes are repeated until there is no more change in the value of any of the cluster centers. Cluster centers represent the locations of FPCs, each serving schools in the respective cluster. It is not allowed the schools to be members of more than one cluster. The demand is aggregated from schools to FPCs; thus, FPCs perform as demand points in our network structure.

The second stage of our solution method presents a multi-objective MILP that includes Constraints (3)-(4) and (6)-(12) in the above formulation. Variables $z_{g}$ and $d_{g}^{\prime}$ are not decision variables in the new model as they are determined in the first step of the solution approach; thus, 
Constraints (6) and (8) become linear constraints. To linearize Constraints (11) and (12), we replace them with (23)-(26). Constraints (23) impose that the total transported amount from a farmer to DCs cannot exceed the capacity of vehicle $t$. Contraints (24) ensure that if vehicle $t$ travels between farmer $f$ and DC $r$, then $x_{f r}^{t}$ takes a value of 1 , where $M$ is a very big number. Similar constraints between DCs and FPCs are represented by Constraints (25) and (26).

$$
\begin{array}{ll}
\sum_{r \in R} x_{f r}^{t} \leq C V_{t} & \forall t \in T, f \in \mathrm{F} \\
x_{f r}^{t} \leq M p_{f r}^{t} & \forall t \in T, f \in \mathrm{F}, r \in \mathrm{R} \\
\sum_{g \in \mathrm{G}} x_{r g}^{k} \leq C V_{k} & \forall k \in \mathrm{K}, r \in \mathrm{R} \\
x_{r g}^{k} \leq M p_{r g}^{k} & \forall k \in \mathrm{K}, r \in \mathrm{R}, \mathrm{g} \in \mathrm{G}
\end{array}
$$

All terms related to the third echelon are removed from the first objective function. The second one remains the same as it minimizes the total travel time in the first and second echelons. We offer a weighted sum approach to transfer this multi-objective model to a single objective, as we are optimizing both objectives simultaneously. In the weighted sum approach, the solution $x$ is obtained based on a scalar composite function $f(x)$, the weighted sum of the $n$ objectives.

$f_{\mathrm{i}}(x)=\lambda_{1} f_{1}(x)+\lambda_{n} f_{2}(x)+\cdots+\lambda_{n} f_{n}(x)$

where $\lambda_{i}$ is a non-negative constant weight for $f_{i}(x)\left(\sum_{i=1}^{n} \lambda_{i}=1\right)$. Different weights can be assigned to objectives based on the preferences of the decision-maker. Thus, the method allows us to investigate results under various scenarios for different weights of objectives.

\section{CASE STUDY}

There are 13 provinces in Turkey's Central Anatolia region where 723,574 students were studied in 2589 public primary schools in 2019 (MoE, 2020). The number of students in each school was obtained from the Ministry of National Education of the Republic of Turkey, and schools' exact locations were determined via Google Maps. The locations of farmers were selected from the areas 
where the agricultural activities are high. We assume that DCs cannot provide food from other provinces outside of Central Anatolia. Thus, local farmers should be supported, and students should be provided with healthy and fresh food. Fifteen locations are identified for local farmers, represented by yellow markers on Central Anatolia's map in Figure 2. Eight potential locations for DCs selected from industrial and logistics zones close to intercity highways are shown in black in Figure 2. Data collected for schools, farmers, and DC are summarized in Table 1.

Table 1. Number of schools and students in Central Anatolia

\begin{tabular}{|c|c|c|c|c|c|}
\hline No. & Province & $\begin{array}{c}\text { Number of } \\
\text { Schools } \\
\end{array}$ & $\begin{array}{c}\text { Number of } \\
\text { Students }\end{array}$ & $\begin{array}{c}\text { Region of Local } \\
\text { Farmers }\end{array}$ & Region of DCs \\
\hline 1 & Ankara & 588 & 292,914 & $\begin{array}{c}\text { Gölbaşı } \\
\text { Ayaş } \\
\text { Akșehir }\end{array}$ & $\begin{array}{c}\text { Ankara Logistics } \\
\text { Base } \\
\text { Kayacık }\end{array}$ \\
\hline 2 & Konya & 574 & 138,428 & Ereğli & $\begin{array}{l}\text { Logistics Base } \\
\text { B. Köprü }\end{array}$ \\
\hline 3 & Kayseri & 316 & 87,753 & Yeşilhisar & Logistics \\
\hline 4 & Eskişehir & 119 & 39,506 & Mihalgazi Sera & \\
\hline 5 & Sivas & 226 & 33,772 & Suşehri & $\begin{array}{l}\text { Sivas Industry } \\
\text { Zone }\end{array}$ \\
\hline 6 & Kırıkkale & 58 & 13,765 & Keskin & - \\
\hline 7 & Aksaray & 150 & 25,283 & $\begin{array}{c}\text { Merkez } \\
\text { Ermenek Gülsu }\end{array}$ & - \\
\hline 8 & Karaman & 66 & 13,161 & Vadisi & Kırşehir Industry \\
\hline 9 & Kırşehir & 56 & 11,194 & Kaman & Zone \\
\hline 10 & Niğde & 140 & 22,427 & Bor & - \\
\hline 11 & Nevşehir & 115 & 17,442 & Ürgüp & $\begin{array}{l}\text { Industry Zone } \\
\text { Yozgat Industry }\end{array}$ \\
\hline 12 & Yozgat & 136 & 19,834 & Merkez & Zone \\
\hline \multirow[t]{2}{*}{13} & Çankırı & 45 & 8,095 & Ayan & $\begin{array}{c}\text { Çankırı Industry } \\
\text { Zone }\end{array}$ \\
\hline & Total & 2589 & 723,574 & & \\
\hline
\end{tabular}

As mentioned earlier, the locations of FPCs were determined by the K-means clustering method. The number of cluster centers was set according to the intervals indicated in Table 2, where $x$ 
represents the number of schools in each province. For example, while provinces with 151 to 251 schools have two cluster centers, there are five cluster centers in provinces with more than 500 schools. As a result, 31 FPC locations were determined in the Central Anatolia Region: five in Ankara and Konya (1-5, 11-15), two in Eskişehir (6-7), one each in Çankırı, Kırıkıkle, Kırşehir, and Karaman $(8,9,10,31)$ and, three in Sivas $(26-28)$, two each in Aksaray $(16,17)$, Nevşehir $(18,19)$, Niğde $(29,30)$ and Yozgat $(20,21)$, four in Kayseri (22-25). The coordinates of the cluster centers are shown with blue markers in Figure 2. Schools receive service from the FPC in their cluster center. When primary school students in Turkey attend school an average of 180 days per year, and a student's daily lunch is at least 125 grams, the total annual demand per school is calculated by multiplying the number of students by $22.5 \mathrm{~kg} / \mathrm{year}$. Demand at each cluster center (FPC) is determined by summing the demands of the schools in that cluster.

Table 2. Number of clusters

\begin{tabular}{cl}
\hline \# of Clusters & \# of Schools \\
\hline 1 & $0 \leq \mathrm{x} \leq 75$ \\
2 & $75 \leq \mathrm{x} \leq 151$ \\
3 & $151 \leq \mathrm{x} \leq 251$ \\
4 & $251 \leq \mathrm{x} \leq 500$ \\
5 & $\mathrm{x} \geq 500$ \\
\hline
\end{tabular}

Table 3 shows the characteristics of the vehicles used in both echelons. In the first echelon, we use larger vehicles such as trucks, as the transportation is intercity between farmers and DCs. In the second echelon, we use pickup trucks due to their lower capacity and lower carbon dioxide emissions to the urban area. While capacity and speed values are set close to reality for these vehicles, variable costs are determined in parallel with vehicle capacities. The speed limit is 80 $\mathrm{km} / \mathrm{h}$, which is the upper limit for two-way intercity highways determined by the General Directorate of Highways of Turkey. The values of parameters $\mathrm{PCO}_{2}, \mathrm{WCO}_{2}, \mathrm{~V}_{\text {eff }}$ are set as given in 
Jabir et al. (2017). The weight of each product delivered $(W)$ is taken as equal to the gross weight of a meal, which is 0.000130 tons.

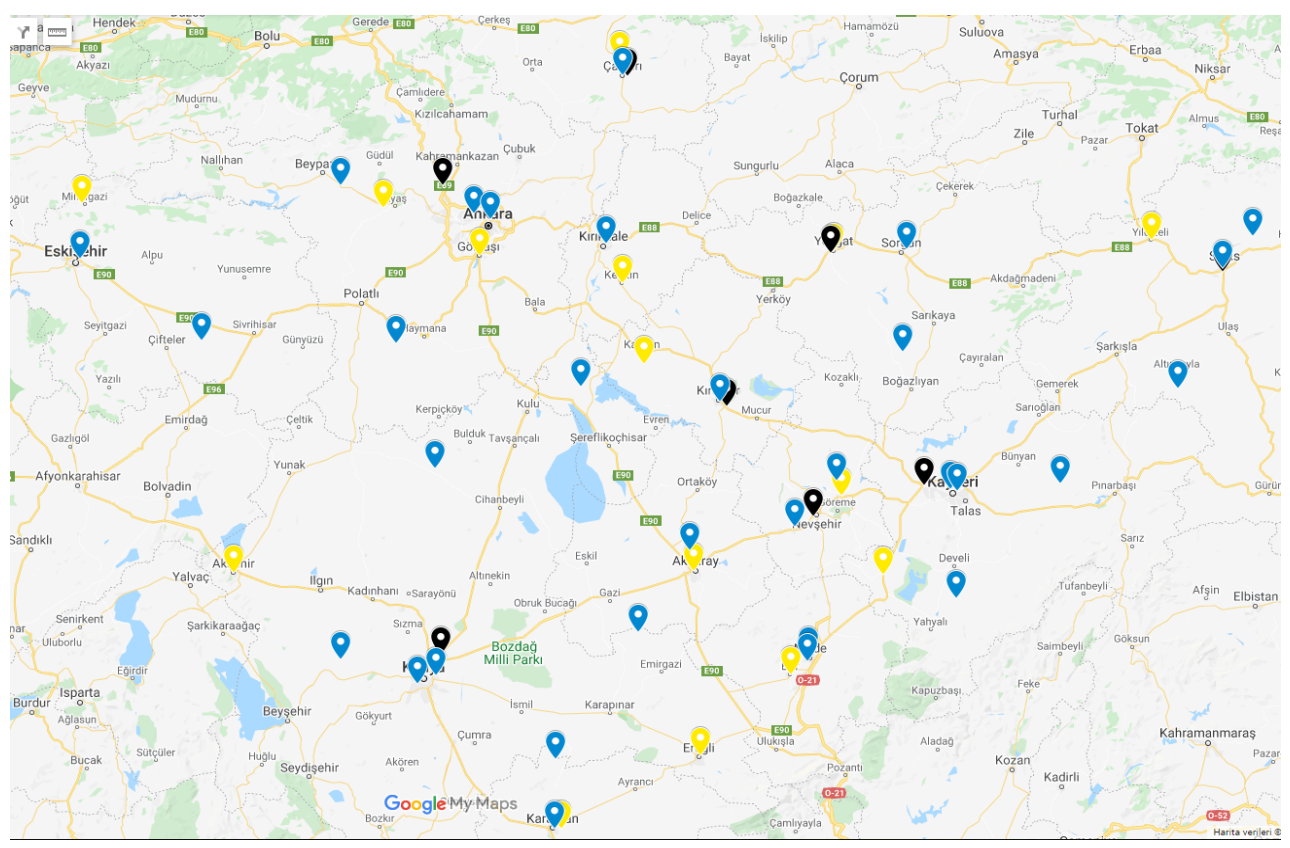

Figure 2. The locations of farmers, DCs, and FPCs on the Central Anatolia map

Table 3. The characteristics of vehicles

\begin{tabular}{ccccc}
\hline Echelon & Types of Vehicles & $\begin{array}{c}\text { Fuel Consumption } \\
\text { (lt./km) }\end{array}$ & $\begin{array}{c}\text { Variable Cost } \\
\text { (TL.) }\end{array}$ \\
\hline From & 1 & 1.2 & 15,000 & 1000 \\
farmers to & 2 & 1.4 & 17,000 & 2000 \\
DCs & 3 & 1.5 & 20,000 & 3000 \\
\hline & 1 & 0.8 & 8,500 & 200 \\
From DCs to & 2 & 1 & 10,000 & 300 \\
FPCs & 3 & 1.2 & 11,000 & 400 \\
\hline
\end{tabular}

\section{DISCUSSIONS OF THE CASE STUDY RESULTS}

In this section, we discuss the results of the case study. The proposed MILP was solved via GAMS 24.1 on an Intel Xeon CPU E5-2620 0, 2.0 GHz CPU, and 88 GB RAM computer.

In the weighted sum approach, we generate nine different scenarios to enable the decision-maker to evaluate model results for different weights of objectives. The two objectives are conflicting, as 
minimizing the total cost requires establishing fewer DCs and using fewer vehicles, which increases the total travel time on the network. While Table 4 shows the scenarios, Table 5 reports the model results obtained by normalizing objective functions for each scenario, as they have different units of measures. The first two scenarios are single-objective models, where the total cost or total travel time is optimized. The results obtained in Scenarios 1, 2, and 5 dominate the results obtained in Scenarios 3, 4, and 6-9. Therefore, Scenarios 1, 2, and 5 provide non-dominated Pareto-optimal solutions, meaning that these scenarios are not superior to each other in terms of both objective functions. If the decision-maker can prioritize the objectives, they can either select the first or second scenario; otherwise, it is best to weigh them equally. In scenario 1, 5 DCs are established at nodes $1,5,9,11$, and 12 . Since vehicles in the first echelon have higher capacities, five first type of vehicles are dispatched here. 33 first type of vehicles are used in the second echelon. In scenario 2 , all eight DCs are established as expected. Thus, the total travel time is minimized with more vehicles and more DCs, without considering the total cost. Eight vehicles (six of the first type, two of the second type) and 32 vehicles (13 of the first type, eight of the second type, and 11 of the third type) are dispatched in the first and second echelons. In scenario 5, seven DCs established at nodes 1, 2, 5, 9, 11, 12, and 13; eight vehicles (four of the first type, four of the third type of vehicle) and 22 vehicles (18 of the first type, eight of the second type and two from the third type) are dispatched in the first echelon and second echelons, respectively.

Table 4. The weights of objectives

\begin{tabular}{cccccccccc}
\hline Sc. & $\mathbf{1}$ & $\mathbf{2}$ & $\mathbf{3}$ & $\mathbf{4}$ & $\mathbf{5}$ & $\mathbf{6}$ & $\mathbf{7}$ & $\mathbf{8}$ & $\mathbf{9}$ \\
\hline $\boldsymbol{w}_{\mathbf{1}}$ & 1 & 0 & 0.25 & 0.75 & 0.5 & 0.4 & 0.6 & 0.2 & 0.8 \\
$\boldsymbol{w}_{\mathbf{2}}$ & 0 & 1 & 0.75 & 0.25 & 0.5 & 0.6 & 0.4 & 0.8 & 0.2 \\
\hline
\end{tabular}


Table 5. Solutions of Scenarios

\begin{tabular}{ccccccccccc}
\hline Obj./Sc. & $\mathbf{1}$ & $\mathbf{2}$ & $\mathbf{3}$ & $\mathbf{4}$ & $\mathbf{5}$ & $\mathbf{6}$ & $\mathbf{7}$ & $\mathbf{8}$ & $\mathbf{9}$ \\
\hline $\boldsymbol{z}_{\mathbf{1}}$ & & & & & & & & & \\
$\left(10^{3}\right.$ TL.) & 3651652 & 6946320 & 17640300 & 16237600 & 4886996 & 17373400 & 5893230 & 16357300 & 4959555 \\
$\boldsymbol{z}_{\mathbf{2}}$ (hr.) & 810.675 & 521.125 & 2180.225 & 2052.888 & 683.825 & 2203.225 & 37773.413 & 2118.425 & 798.013 \\
\hline
\end{tabular}

\section{CONCLUSION}

This paper addresses the location and routing problem encountered in designing a school lunch distribution network. We first present a multi-objective MINLP formulation of the problem. Since the problem is Np-hard, we develop a two-stage approach to solve it. The first stage presents a Kmeans clustering method, which finds the locations of FPCs, allocates the schools to FPCs, and allows to compute the demand of FPCs accordingly. The second stage solves a multi-objective MILP to determine the locations of DCs and the quantities transported between nodes by heterogeneous vehicles. A weighted sum approach simultaneously optimizes the two conflicting objectives: minimizing the total cost, including the cost of $\mathrm{CO}_{2}$ emissions, and minimizing total travel time to preserve the freshness of perishable products. We solve the model for nine different weights of objectives.

A case study was conducted in the Anatolian region of Turkey, where NSLP is planned to be implemented soon. The results show that 31 FPCs are required to be established to meet the demand of schools. Regarding the locations and numbers of DCs, we obtain three non-dominated solutions from which decision-makers can choose one based on the importance of the objectives. Each solution provides information on where DCs will be located, which vehicle will realize the route, which schools will be served from each DC. The results reveal the total cost of designing an NSLP network with minimum transportation time. The total travel time across the network is at least 21.7 days, accounting for $12.06 \%$ of the entire school days. The minimum cost of realizing the network is 
3,651,652,000 TL. If objectives are given equal weight as in Scenario five, 28.5 days out of 180 school days correspond to total travel time. The total design cost is 4,886,996,000 TL, including the installation of 31 FPCs and seven DCs, and fixed operational and carbon emission costs of 30 vehicles in both echelons. The case study results generate essential information that may provide the ability to estimate the National School Lunch Program's cost on a regional basis. Decision-makers can benefit from these results in preparing management strategies at regional and provincial levels and drawing conclusions about their investment needs.

It should be noted that this study may also have limitations. For example, the solved problem allocates the schools to FPCs; however, it does not find specific vehicle routes. In the future, routing decisions between FPCs and schools can be considered. This problem is called the multi-echelon transportation location routing problem, which is again an Np-hard problem. Therefore, it requires the development of meta-heuristic methods to solve large-size problems. Also, different features of vehicle routing problems such as time windows and open routing can be adapted to the distribution of NSLP. In addition, a multi-commodity distribution model can be developed by incorporating intercity and urban traffic congestion. 


\section{REFERENCES}

Biuki, M., Kazemi, A. \& Alinezhad, A. 2020. An integrated location-routing-inventory model for sustainable design of a perishable products supply chain network. Journal of Cleaner Production. 260: 120842. https://doi.org/10.1016/j.jclepro.2020.120842

Bundy, D., Burbano, C., Grosh, M., Gelli, A., Jukes, M. \& Drake, L. 2009. Rethinking School Feeding: Social Safety Nets, Child Development and Education Sector. The International Bank for Reconstruction and Development, Washington. ISBN-10 : 0821379747

Candaş, A., Akkan, B.E., Günseli, S. \& Deniz, M.B. 2011. Devlet İlköğretim Okullarinda Ücretsiz Öğle Yemeği $\quad$ Sağlamak $\quad$ Mümkün $\quad$ Mü? https://spf.boun.edu.tr/sites/spf.boun.edu.tr/files/1439801191_spf_okulda_yemek_raporu_0.pdf

Dai, Z., Aqlan, F., Zhenga, X. \& Gao, K. 2018. A location-inventory supply chain network model using two heuristic algorithms for perishable products with fuzzy constraints. Computers \& Industrial Engineering. 119: 338-352. https://doi.org/10.1016/j.cie.2018.04.007

Drezner, Z. \& Scott, C.H. 2013. Location of a distribution center for a perishable product. Math Meth Oper Res. 78: 301-314. https://doi.org/10.1007/s00186-013-0445-6

Epstein, R., Henriquez, L., Catalán, J., Weintraub, G.Y., Martinez, C. \& Espejo, F. 2004. A combinatorial auction improves school meals in Chile: A case of OR in developing countries. International Transactions in Operational Research. 11(6): 593-612. https://doi.org/10.1111/j.1475-3995.2004.00480.x

FRAC, Food Research and Action Center. 2021. Benefits of School Lunch. https://frac.org/programs/national-school-lunch-program/benefits-school-lunch

Ghezavati, V.R., Hooshyar, S. \& Tavakkoli-Moghaddam., R. 2015. A benders' decomposition algorithm for optimizing distribution of perishable products considering postharvest biological behavior in agri-food supply chain: a case study of tomato. Cent Eur J Oper Res. 25: 29-54. 
Govindan, K., Jafarian, A., Khodaverdi, R. \& Devika, K. 2014. Two-echelon multiple vehicle location-routing problem with time windows for optimization of sustainable supply chain network of perishable food. Int. J. Production Economics. 152: 9-28.

Hiassat, A., Diabat, A. \& Rahwan, I. 2017. A genetic algorithm approach for location-inventoryrouting problem with perishable product. Journal of Manufacturing Systems. 42: 93-103.

Jabir, E., Panicker, V. V. \& Sridharan, R. 2017. Design and development of a hybrid ant colonyvariable neighborhood search algorithm for a multi-depot green vehicle routing problem. Transportation Research Part D. 57: 422-457. https://doi.org/10.1016/j.trd.2017.09.003

Jokinen, J., Raty, T. \& Lintonen, T. 2019. Clustering structure analysis in time-series data with density-based clusterability measure. IEEE/CAA J. Autom. Sinica 6(6): 13321343. https://doi.org/ 10.1109/JAS.2019.1911744

Kretschmer, A., Spinler, S. \& Van Wassenhove, L. N. 2014. A School Feeding Supply Chain Framework: Critical Factors for Sustainable Program Design. Production and Operations Management. 23(6): 990-1001. https://doi.org/10.1111/poms.12109

Manzini, R. \& Bindi, F. 2009. Strategic design and operational management optimization of a multi stage physical distribution system. Transportation Research Part E. 45: 915-936.

Milliyet, 2020. School Lunch Program. https://www.milliyet.com.tr/gundem/18-5-milyonogrenciye-ucretsiz-yemek-geliyor-6141418

$\begin{array}{lllll}\text { Ministry of } & \text { National } & \text { Sducation }\end{array}$ https://www.meb.gov.tr/baglantilar/okullar/index.php (2020). Last accessed: 31 August 2020.

Nagy, G., \& Salhi, S. 2007. Location-routing: Issues, models and methods. European Journal of Operational Research. 177 (2): 649-672. https://doi.org/10.1016/j.ejor.2006.04.004 
Olivares, M., Weintraub, G. Y., Epstein, R. \& Yung, D. 2012. Combinatorial Auctions for Procurement: An Empirical Study of the Chilean School Meals Auction. Management Science. 58_(8): iv-1592. https://doi.org/10.1287/mnsc.1110.1496

Orjuela-Castro, J. A., Sanabria- Coronado, L.A. \& Peralta- Lozano, A. M. 2017. Coupling facility location models in the supply chain of perishable fruits. Research in Transportation Business \& Management. 24: 73-80. https://doi.org/10.1016/j.rtbm.2017.08.002

Rafie-Majd, Z., Pasandideh, S.H.R. \& Naderi, B. 2018. Modeling and solving the integrated inventory-location-routing problem in a multi-period and multi-perishable product supply chain with uncertainty: Lagrangian relaxation algorithm. Computers and Chemical Engineering. 109: 9-22. https://doi.org/10.1016/j.compchemeng.2017.10.013

Ralston, K., Newman, C., Clauson, A., Guthrie, J. \& Buzby, J. 2008. U.S Department of Agriculture (USDA), Food and Nutrition Service, The National School Lunch Program: Background, Trends, and Issues. https://www.ers.usda.gov/webdocs/publications/46043/12051_err61_1_.pdf?v=8546.7

Wang, Y., Assogba, K., Liu, Y., Ma, X., Xu, M. \& Wang, Y. 2018. Two-echelon location-routing optimization with time windows based on customer clustering. Expert Systems with Applications. 104: 244-260. https://doi.org/10.1016/j.eswa.2018.03.018 